\title{
PERAN INTENSITAS KOMUNIKASI, KEPERCAYAAN, DAN DUKUNGAN SOSIAL TERHADAP KEBAHAGIAAN PERKAWINAN PADA ISTRI TENTARA SAAT MENJALANI LONG DISTANCE MARRIAGE (LDM) DI BATALYON INFANTERI 407/PADMAKUSUMA KABUPATEN TEGAL
}

\author{
Riza Muhardeni \\ Universitas Ahmad Dahlan, Yogyakarta \\ Email: zha_leony@yahoo.com
}

\begin{abstract}
Abstrak
Penelitian ini bertujuan untuk mengetahui peran intensitas komunikasi, kepercayaan dan dukungan sosial terhadap kebahagiaan perkawinan pada istri tentara saat menjalani long distance marriage. Data dikumpulkan dengan menggunakan kuesioner berisi skala kebahagiaan perkawinan, skala intensitas perkawinan, skala kepercayaan perkawinan serta skala dukungan sosial. Jumlah subjek dalam penelitian ini 80 orang istri tentara yang ditinggal tugas oleh suaminya dan menetap di asrama Batalyon. Teknik analisis data yang digunakan dalam penelitian ini adalah analisis regresi linier berganda. Berdasarkan hasil analisis regresi berganda diperoleh kesimpulan: (1) terdapat peran intensitas komunikasi, kepercayaan dan dukungan sosial terhadap kebahagiaan perkawinaan pada istri tentara saat menjalani long distance marriage, diperoleh $R^{2}=.68, \quad F(3,76)=54,56, p<0,001 ;$ (2) ada peran intensitas komunikasi perkawinan terhadap kebahagiaan perkawinan pada istri tentara saat menjalani long distance marriage $(\beta=.45, p<.001)(3)$ ada peran kepercayaan perkawinan terhadap kebahagiaan perkawinan pada istri tentara saat menjalani long distance marriage, diperoleh ( $\beta=.59, \quad p<.001) ;(4)$ tidak ada peran dukungan sosial terhadap kebahagiaan perkawinan pada istri tentara saat menjalani long distance marriage $(\beta=0,18, p=.054)$.
\end{abstract}

Kata kunci: kebahagiaan perkawinan; intensitas komunikasi perkawinan; kepercayaan perkawinan; dukungan sosial

\footnotetext{
Abstract

The objectives of the study was to examine the role of communication intensity, trust and social support on marital happiness among soldiers' wives whose long distance marriage. Data were collected by asking participants to fill a set of questionnaires that includes marital happiness scale, intensity of marital communication scale, marital trust scale and social support scale. Participants of presents study were 80 wives of the soldiers who are staying at the dormitory of Batalyon. The technique of data analysis applied in this study is multiple linier regression. Based on the result of the multiple linier regression technique, it is concluded: (1) there was a significant influence of communication intensity, trust, and social support on marital happiness among the wives of out of town duty soldier's $(F=54.564, \quad p=0.000)$; (2) there is a very significant influence of communication intensity toward marital happiness among the wives of out of town duty soldier's, $t=5.057, p=0.000$ ( $p>0.05)$; (3) there was a very significant influence of trust toward marital happiness among the wives of out of town duty soldier's, it is obtained $t=3.869, p=0.000(p<0.05)$; (4) there was no significant influence of social support toward marital happiness among the wives of out of town duty soldier's, it is obtained $t=1.959, p=0.054(p<0.05)$.
} 
Keywords: marital happiness; the intensity of marital communication; marital trust; social support

\section{Pendahuluan}

Kebahagiaan dalam pernikahan merupakan dambaan setiap pasangan. Menurut Rauer dan Volling (2013) kebahagiaan dalam pernikahan itu diperlukan agar terhindar dari perasaan stres dan tertekan. Untuk menciptakan kebahagiaan tersebut maka harus ada rasa saling cinta dan komitmen dari kedua pasangan tersebut (Rauer \& Volling, 2013). Dalam sebuah pernikahan, kebahagiaan merupakan salah satu hal yang menjadi tujuan yang diharapkan, pernikahan menuntut adanya perubahan gaya hidup, menuntut adanya persiapan dan penyesuaian diri terhadap tuntutan peran dan tanggung jawab yang baru baik dari suami maupun istri (Fatma \& Sakdiyah, 2015). Sebuah pernikahan yang berhasil adalah harapan setiap pasangan yang telah menikah. Namun demikian, kenyataannya kebahagiaan pernikahan tidak selalu dapat diperoleh dengan cara mudah. Salah satu faktor yang dapt mengganggu kebahagiaan dalam pernikahan, jika tidak dikelola dengan baik, adalah ketika pasangan mesti terpisah secara geografis, atau yang dikenal dengan long distance marriage (LDM).

LDM menggambarkan tentang situasi pasangan yang berpisah secara fisik, salah satu pasangan harus pergi ke tempat lain demi suatu kepentingan, sedangkan pasangan yang lain harus tetap tinggal di rumah. Keadaan berpisah tempat tinggal ini menyebabkan individu mengalami berbagai kondisi psikologis yang dirasakan seperti stres, merasa kesepian, cemas, emosi yang kurang stabil, dan ragu terhadap pasangan (Maguire \& Kinney, 2010; Stafford, 2005).

Pasangan yang menjalani LDM tentu saja menghadapi masalah yang berbeda dengan pasangan suami istri yang tinggal bersama. Dengan menggunakan perspektif teori kelekatan (attachement theory), Pistole (2010) menjelaskan bahwa pernikahan pada dasarnya pernikahan bertujuan untuk membuat ikatan emosional dan ada upaya-upaya khusus untuk mempertahankan ikatan tersebut, salah satunya adalah dengan menjaga kedekatan jarak fisik. Hubungan jarak jauh menjadikan upaya tersebut sulit dilakukan. Sejalan dengan Pistole, hasil penelitian yang dilakukan oleh Marini dan Julinda (2010) menunjukkan bahwa ketiga subjek penelitian yang menjalani pernikahan jarak jauh terdapat beberapa permasalahan dalam hubungan pernikahannya seperti ketidakpuasan dengan aktivitas seksual dan sering merasa cemburu ketika melihat orang lain bisa berkumpul dengan pasangan. Seorang istri yang hidup berjauhan dengan suaminya dapat menimbulkan perasaan kesepian. Bentuk kesepian yang dirasakan berupa karakteristik emosi wujud kesepian yang digambarkan oleh istri yang menjalani pernikahan jarak jauh seperti merasa rindu, khawatir, dan curiga dengan suami saat menjalani hubungan pernikahan jarak jauh serta mengalami kelelahan dalam mengurus anak tanpa dampingan suami (Mijilputri, 2015).

Menurut Rini (2009) pasangan yang menjalani perkawinan jarak jauh memiliki kecenderungan akan mengalami perceraian. Penelitian yang dilakukan oleh Rindfuss dan Stephen (1990) menunjukkan bahwa pada pasangan jarak jauh kemungkinan untuk bercerai lebih besar. Hal tersebut sangat mungkin terjadi karena potensi konflik dari kondisi ini sangat besar, banyak permasalahan yang muncul, misalnya rasa tidak percaya terhadap pasangannya, kecemburuan, rasa rindu dan ingin segera bertemu serta persoalan lainnya. Berdasarkan uraian di atas, diketahui bahwa perkawinan jarak jauh memiliki banyak tantangan. Pertanyaannya adalah, apa saja faktor-faktor yang 
dapat memprediksi kebahagiaan dalam pernikahan jarak jauh tersebut? Penelitian ini berupaya menjawab pertanyaan tersebut dengan mengukur tiga faktor utama, yaitu intensitas komunikasi, kepercayaan, dan dukungan sosial. Sebelum menjelaskan dengan lebih rinci faktor-faktor tersebut, berikut akan dijelaskan terlebih dahulu kebahagiaan dalam pernikahan.

Menurut Rauer dan Volling (2013) kebahagiaan dalam pernikahan itu diperlukan agar terhindar dari perasaan stres dan tertekan. Untuk menciptakan kebahagiaan tersebut maka harus ada rasa saling cinta dan komitmen dari kedua pasangan tersebut (Rauer \& Volling, 2013). Dalam sebuah pernikahan, kebahagiaan merupakan salah satu hal yang menjadi tujuan yang diharapkan, pernikahan menuntut adanya perubahan gaya hidup, menuntut adanya persiapan dan penyesuaian diri terhadap tuntutan peran dan tanggung jawab yang baru baik dari suami maupun istri (Fatma \& Sakdiyah, 2015). Sebuah pernikahan yang berhasil adalah harapan setiap pasangan yang telah menikah, seperti yang telah dicetuskan Burgess dan Locke (Habibi, 2015) ada enam kriteria dalam mengukur keberhasilan sebuah pernikahan yaitu awetnya suatu pernikahan, kebahagiaan suami dan istri, kepuasan pernikahan, penyesuaian seksual, penyesuaian pernikahan dan terakhir yaitu persatuan pasangan. Hasil penelitian yang dilakukan oleh Zhang dan Tsang (2012) menunjukkan bahwa wanita yang menikah dengan suami yang berpenghasilan rendah cenderung kurang bahagia dengan pernikahannya, tetapi efek ini akan diatasi jika lebih banyak cinta dalam arti perhatian yang tulus tentang kesejahteraan mitra dan bersedia berkorban untuk pasangannya.

Faktor pertama yang berperan penting dalam mempengaruhi kebahagiaan dalam pernikahan jarak jauh adalah intensitas komunikasi. Dengan menggunakan teori interdependence, Stafford (2010) menjelaskan bahwa pasangan dengan pernikahan jarak jauh memiliki keterbatasan dalam berkomunikasi. Hal ini pada gilirannya dapat menyebabkan ketergantungan pasangan satu sama lain semakin menurun dan selanjutnya akan berdampak pada kualitas hubungan. Selain itu, tidak adanya komunikasi tatap muka menyebakan ketidakmampuan dalam memberikan kepedulian secara fisik seperti memeluk, ketika berada dalam kondisi LDM (Marvin \& Britner, 1999). Untuk mengatasi hambatan dalam komunikasi secara langsung, beberapa pasangan memilih menggunakan media berbasis internet untuk berkomunikasi (Billedo, Kerkhorf, \& Finkenauer, 2015).

Intensitas komunikasi merupakan tingkat kedalaman penyampaian pesan dari individu sebagai anggota keluarga kepada yang lainnya (Djamarah, 2004). Intensitas komunikasi mencakup aspek seperti kejujuran, keterbukaan, pengertian, percaya yang mutlak diantara kedua belah pihak dan dukungan (Oslon, 1992). Diharapkan semakin sering anggota keluarga dalam hal ini pasangan suami istri berinteraksi, maka kepercayaan dapat tercipta sehingga hal tersebut dapat menimbulkan kebahagiaan dalam diri pasangan. Penelitian yang dilakukan oleh Sasmita (2014) menunjukkan bahwa kebahagiaan dipengaruhi intensitas komunikasi sebesar $24,3 \%$ dan sisanya $75,7 \%$ dipengaruhi oleh faktor lain yang mempunyai pengaruh lebih besar. Menurut Yoseph (Andjariah, 2005) suami istri harus mampu menciptakan komunikasi yang harmonis dalam keluarga, sebab komunikasi harmonis akan memungkinkan adanya saling pengertian dan ketulusan terhadap segala aspek kehidupan itu sendiri.

Hasil penelitian yang dilakukan oleh Dewi dan Sudhana (2013) juga menunjukkan bahwa terdapat hubungan yang positif antara komunikasi interpersonal pasutri dengan keharmonisan dalam pernikahan. Adapun besar sumbangan efektif yang diberikan komunikasi interpersonal pasutri dengan keharmonisan pernikahan sebesar $42,2 \%$ dan sisanya sebesar $57,8 \%$ dipengaruhi oleh faktor-faktor lain yang tidak diteliti dalam penelitian ini. 
Hasil penelitian yang dilakukan oleh Aryani (2009) menunjukkan bahwa komunikasi interpersonal sangat penting sekali digunakan dalam pasangan suami istri untuk menjaga keluarga yang utuh dan harmonis.

Dalam studi pada istri-istri tantara di United States (US), Merolla (2010) menemukan bahwa keterbatasan waktu, kuantitats, dan konten komunikasi merupakan salah satu hambatan dalam menjaga relasi ketika suami mendapat tugas di tempat yang jauh. Namun demikian, itu berarti pasangan LDM tidak mampu mengatasi keterbatasan tersebut. Studi Merolla menunjukkan bahwa para pasangan istri dan suami tantara tersebut memiliki berbagai strategi untuk mengatasi masalah komunikasi yang dihadapi, seperti menggunakan media komunikasi email dan rutin mengabari kegiatan-kegiatan yang dilakukan seharihari untuk mempertahankan adanya rutinitas pasangan. Dengan cara-cara tersebut menjelaskan bahwa kebahagiaan pernikahan dapat dipertahankan (Karney \& Crown, 2007; Merolla, 2010,). Selain itu, komunikasi tanpa tatap muka tersebut dapat memberikan dampak positif bagi hubungan jarak jauh karena keterbatasan cues menyebakan individu cenderung bias menilai lawan bicara dan pada gilirannya melakukan idealization terhadap lawan bicara tersebut (Crystal Jiang \& Hanchock, 2013).

Serupa dengan penelitian Merolla (2010), penelitian ini juga berupaya memahami kebahagiaan pasangan LDM dengan menggunakan istri tantara sebagai partisipan. Namun berbeda dengan penelitian tersebut yang menggunakan metode kualitatif untuk mengumpulkan data, pada penelitian ini peneliti menggunakan metode kuantitatif.

Faktor kedua yang diduga mampu memprediksi kebahagiaan jarak jauh adalah kepercayaan. Hal ini didasari pada temuan Fatima dan Ajmal (2012) yang menunjukkan bahwa rasa percaya adalah salah satu dari enam belas faktor yang mempengaruhi kebahagiaan dalam ke- hidupan pernikahan pada wanita. Faktor lainnya yaitu kesamaan agama, kepuasan, kompromi, cinta, care, saling memahami, komunikasi, perbedaan usia, ketulusan dan respect, saling berbagi, saling memaafkan, tempramen pasangan, kekuatan menjaga anak, struktur keluarga, pendidikan dan status hubungan hukum yang positif. Selain itu, hasil penelitian yang dilakukan oleh Pratamasari (2016) juga menunjukkan adanya peranan rasa percaya (trust) dalam sebuah hubungan.

Hal lain yang dapat mempengaruhi kebahagiaan pernikahan, terutama LDM adalah dukungan sosial. Dukungan sosial adalah informasi atau umpan balik dari orang lain yang menunjukkan bahwa seseorang dicintai dan diperhatikan, dihargai, dan dihormati, dan dilibatkan dalam jaringan komunikasi dan kewajiban yang timbal balik (King, 2012). Dukungan sosial didefinisikan oleh Wills, (Sears, Freedman, \& Peplau, 1994) sebagai pertukaran yang terjadi secara interpersonal ketika seseorang memberikan bantuan atau dukungan kepada orang lain. Menurut Gottlieb (Kenrick, Neuberg, \& Cialdini, 2007) dukungan sosial didefinisikan sebagai bantuan secara emosional, informasional ataupun material yang diberikan oleh orang lain.

Manusia sebagai makhluk sosial tidak dapat hidup sendirian tanpa bantuan dari orang lain. Kebutuhan fisik (sandang, pangan, papan), kebutuhan sosial (pergaulan, pengakuan) dan kebutuhan psikis termasuk rasa ingin tahu, rasa aman, perasaan religiusitas, tidak mungkin terpenuhi tanpa bantuan orang lain, apalagi jika orang tersebut sedang menghadapi masalah, baik ringan maupun berat. Pada saat-saat seperti itu seseorang akan mencari dukungan sosial dari orang-orang disekitarnya, sehingga dirinya merasa dihargai, diperhatikan dan dicintai. Hasil penelitian yang dilakukan oleh Margianti dan Ekayati (2013) menunjukkan bahwa terdapat hubungan yang sangat signifikan antara stres dan dukungan keluarga dengan agresivitas 
pada istri yang menjalani pernikahan jarak jauh. Seorang istri yang menjalani pernikahan jarak jauh juga membutuhkan dukungan sosial karena mereka memiliki beban dan tanggung jawab hampir sama dengan orang tua tunggal (single parent), dimana ia dihadapkan dengan urusan rumah tangga yang cukup kompleks seorang diri (Margiani \& Ekayati, 2013). Hasil penelitian yang dilakukan oleh Hayati (2011) menunjukkan bahwa hubungan positif yang sangat signifikan antara dukungan sosial pasangan dengan kepuasan perikahan. Artinya semakin tinggi dukungan sosial pasangan maka akan semakin tinggi kepuasan pernikahan. Hasil penelitian yang dilakukan oleh peneliti menunjukkan bahwa tidak ada peran dukungan sosial perkawinan terhadap kebahagiaan perkawinan pada istri tentara saat menjalani long distance marriage. Untuk menguji hipotesis, digunakan analisis regresi berganda.

Hasil penelitian yang dilakukan oleh Anderson, Ryzin \& Doherty (2010) menunjukkan bahwa adanya 5 lintasan yang berbeda. Hampir dua pertiga dari peserta melaporkan tingkat tinggi dan kebahagiaan yang stabil dari waktu ke waktu, dan satu pertiga yang lainnya menunjukkan kebahagiaan yang rendah, kebahagiaan rendah yang kemudian menurun, atau pola lengkung kebahagiaan yang tinggi, penurunan, dan pemulihan. Masalah perkawinan, waktu yang dihabiskan dalam kegiatan bersama, dan (untuk yang lebih rendah derajatnya) kesulitan ekonomi mampu membedakan keanggotaan kelompok lintasan. Hasil penelitian tersebut menunjukkan bahwa kebahagiaan perkawinan mungkin memiliki beberapa ragam lintasan yang cukup berbeda di seluruh populasi.

Setiap pasangan suami istri umumnya menginginkan untuk tinggal bersama di dalam satu rumah, namun ada beberapa keluarga yang tidak tinggal bersama (long distance marriage / LDM) di dalam satu rumah dikarenakan berbagai macam hal (Rachmawati \& Mastuti, 2013).
Salah satu pasangan yang mengalami bentuk pernikahan jarak jauh yang nyata adalah pada pasangan BRIGIF 1 MARINIR TNI-AL (Rachmawati \& Mastuti, 2013). Segala konflik yang ada di Negara Republik Indonesia bisa terjadi dimana saja. Jadi suami seorang marinir TNI-AL harus siap jika ditugaskan kemanapun dan berapa lamapun atas perintas negara. Istri tidak hanya ditinggal sehari atau dua jika suami bertugas. Para anggota dapat ditugaskan dengan kurun waktu berbulan-bulan hingga tahunan sesuai dengan penugasan (Rachmawati \& Mastuti, 2013).

\section{Metode Penelitian}

Teknik pengambilan sampel yang digunakan dalam penelitian ini adalah metode purposive sampling. Metode purposive sampling merupakan metode penetapan responden untuk dijadikan sampel berdasarkan pada kriteria-kriteria tertentu (Siregar, 2013). Subjek dalam penelitian ini adalah istri tentara di wilayah Kabupaten Tegal. Adapun karakteristik subjek dalam penelitian ini adalah istri tentara/ibu persit yang tinggal di kompi yang sedang mengalami long distance marriage (LDM) dengan suami yang sedang mengemban tugas negara dalam kurun waktu berbulan-bulan hingga tahunan sesuai dengan penugasan. Jumlah sampel dalam penelitian ini 80 orang. Pada penelitian ini peneliti membagikan skala kepada responden secara langsung untuk diberikan respon sesuai dengan permintaan dari peneliti.

Alat pengumpulan data yang digunakan adalah skala model Likert yang telah dimodifikasi menjadi empat alternatif jawaban, yaitu SS (Sangat Sesuai), S (Sesuai), TS (Tidak Sesuai) dan STS (Sangat Tidak Sesuai). Aitem-aitem dalam skala ini dikelompokkan dalam aitem favorable (mendukung atau memihak pada objek sikap) dan unfavorable (tidak mendukung objek sikap) (Azwar, 2012). Dalam memberikan penilaian terhadap jawaban yang ada, untuk setiap pernyataan favorabel bernilai dari 4 sampai 1 . Pilihan 
sangat sesuai diberi nilai 4 , pilihan sesuai diberi nilai 3 , pilihan tidak sesuai diberi nilai 2, pilihan sangat tidak sesuai diberi nilai 1 . Sebaliknya untuk pernyataan unfavorabel.

Variabel yang diukur pada penelitian ini adalah kebahagiaan perkawinan sebagai variabel terikat. Intensitas komunikasi perkawinan, kepercayaan perkawinan dan dukungan sosial perkawinan sebagai variabel bebas. Alat ukur kebahagiaan perkawinan dipakai dengan menggunakan teori Gotman (1999). Adapun teknik analisis data yang digunakan dalam penelitian ini adalah teknik analisis regresi linier berganda.

\section{Hasil Penelitian}

Berdasarkan hasil uji validitas skala kebahagiaan perkawinan diperoleh koefisien validitas bergerak antara 0,318 sampai dengan 0,706 . Reliabilitas skala sebesar 0,934. Jumlah item 48, yang valid sebanyak 41 item. Skala intensitas komunikasi diperoleh koefisien validitas antara 0,350 sampai dengan 0,747 . Reliabilitas skala sebesar 0,940. Jumlah item 48, yang valid sebanyak 40 item. Skala kepercayaan diperoleh koefisien validitas antara 0,381 sampai dengan 0,825 . Reliabilitas skala sebesar 0,937. Jumlah item 24, yang valid sebanyak 22 item. Skala dukungan sosial diperoleh koefisien validitas antara 0,352 sampai dengan 0,838 . Reliabilitas skala sebesar 0,949 . Jumlah item 32 , yang valid sebanyak 30 item. Hasil uji kategorisasi diketahui bahwa mayoritas subjek pada penelelitian ini berada pada kategorisasi sangat tinggi.

Berdasarkan hasil analisis uji asumsi: (1) uji normalitas dengan menggunakan metode Kolmogrov-Smirnov, diketahui bahwa besarnya nilai Kolmogrov-Smirnov terhadap keempat variabel dalam penelitian ini adalah 0,612 dan nilai signifikannya adalah 0,848 . Hal ini berarti data terdistribusi normal karena data dikatakan berdistribusi normal jika Asymp. Sig. (2-tailed) > 0,05. (2) uji linieritas diketahui bahwa variabel kebahagiaan perkawinan dengan intensitas komunikasi perkawinan adalah linier dengan $p=0,664$ $(p>0,05)$. Variabel kebahagiaan perkawinan dengan kepercayaan perkawinan adalah linier dengan $p=0,130(p>0,05)$. Variabel kebahagiaan perkawinan dengan dukungan sosial adalah linier dengan $p=0,902$ $(p>0,05)$. (3) uji heteroskedastisitas diketahui bahwa variabel intensitas komunikasi telah terjadi heteroskedastisitas dengan nilai $p=0,047(p>0,05)$. Variabel kepercayaan perkawinan tidak terjadi heteroskedastisitas dengan nilai $p=0,326$ $(p>0,05)$. Variabel dukungan sosial perkawinan tidak terjadi heteroskedastisitas dengan nilai $p=0,478 \quad(p>0,05)$. Jika variabel independen signifikan secara statistik mempengaruhi variabel dependen, maka ada indikasi terjadi heteroskedastisitas. Berdasarkan hasil uji heteroskedastisitas menunjukkan bahwa ada satu variabel bebas memiliki nilai sig. kurang dari 0,05. Hal ini terlihat dari probabilitas signifikansinya di atas tingkat kepercayaan $5 \%$ atau 0,05 . (3) uji multikolinieritas diketahui bahwa tidak ada satu variabel bebas yang nilai tolerance kurang dari 10 persen $(0,1)$ yaitu variabel intensitas komunikasi perkawinan dengan nilai tolerance sebesar 0,350 , kepercayaan perkawinan dengan nilai tolerance sebesar 0,435 dan dukungan sosial perkawinan dengan nilai tolerance sebesar 0,484. Hasil perhitungan VIF juga menunjukkan kondisi yang sama, yaitu semua variabel bebas memiliki nilai VIF kurang dari 10 yaitu variabel intensitas komunikasi perkawinan dengan nilai VIF sebesar 2,859, kepercayaan perkawinan dengan nilai VIF sebesar 2,300 dan dukungan sosial perkawinan dengan nilai VIF sebesar 2,066, sehingga dapat diambil kesimpulan bahwa tidak terdapat masalah multikolinieritas pada model penelitian ini.

Berdasarkan hasil analisis uji hipotesis dengan menggunakan teknik regresi berganda diperoleh hasil bahwa variablevariabel predictor dapat menjelaskan 17.1 $\%$ variasi pada kebahagiaan $\left(R^{2}=0,68\right.$, $F(3,76)=54,56, p<.001$. Hasil ini me- 
Tabel 1. Hasil analisis deskriptif dapat dilihat pada table berikut:

\begin{tabular}{lrrrrr}
\hline \multirow{2}{*}{ Variabel } & \multirow{N}{*}{ (skor X yang telah diperoleh) } \\
\cline { 3 - 6 } & & \multicolumn{1}{c}{ Min } & Maks & \multicolumn{1}{c}{ Mean } & \multicolumn{1}{c}{ SD } \\
\hline Kebahagiaan & 80 & 109 & 161 & 141.43 & 12.07 \\
Intensitas komunikasi & 80 & 111 & 160 & 133.59 & 13.42 \\
Kepercayaan & 80 & 58 & 88 & 76.62 & 7.82 \\
Dukungan Sosial & 80 & 78 & 120 & 96.59 & 10.73 \\
\hline
\end{tabular}

nunjukkan bahwa intensitas komunikasi perkawinan, kepercayaan perkawinan, dan dukungan sosial perkawinan secara bersama-sama atau simultan dapat menjelaskan $68 \%$ varian pada kebahagiaan perkawinan pada istri tentara saat menjalani long distance marriage. Hasil perhitungan analisis regresi berganda dengan menggunakan metode stepwise menunjukkan bahwa intensitas komunikasi perkawinan secara signifikan dapat memprediksi kebahagiaan pernikahan jarak jauh $(\beta=0,445, p<.001)$. Kepercayaan terhadap perkawinan juga ditemukan mampu secara signifikan memprediksi pernikahan jarak jauh $(\beta=0,585$, $p<.001)$. Namun demikian, dukungan sosial diketahui tidak memiliki peranan signifikan dalam memprediksi kebahagiaan dalam pernikahan jarak jauh $(\beta=0,182$, $p=.054)$.

\section{Diskusi}

Hasil penelitian menunjukkan bahwa secara bersama-sama terdapat peran antara intensitas komunikasi, kepercayaan dan dukungan sosial terhadap kebahagiaan perkawinan pada istri tentara saat menjalani longdistancemarriage. Hal ini memperkuat teori yang dikemukakan oleh para ahli bahwa kebahagiaan pernikahan dapat diukur dari sejauhmana suami dan istri memiliki pengetahuan tentang pasangan, memelihara rasa suka dan kagum terhadap pasangannya, saling mendekati, menerima pengaruh dari pasangan, mampu memecahkan masalah dan menciptakan makna bersama di dalam perkawinan (Gottman, 1999). Hal ini juga sesuai dengan penelitian yang dilakukan oleh Rachmawati dan Mastuti (2013) yang menemukan bahwa tidak selamanya pernikahan jarak jauh menimbulkan ketidakbahagiaan dalam hubungan pernikahan. Agar terciptanya kebahagiaan dalam pernikahan, maka pasangan suami istri harus memenuhi faktor-faktor yang mempengaruhi kebahagiaan agar bisa menghadapi tantangan dan hambatan dalam mengarungi rumah tangga terutama pada istri tentara saat menjalani long distance marriage (LDM).

Kepercayaan dan komunikasi merupakan salah satu faktor yang mempengaruhi kebahagiaan dalam hubungan pernikahan seperti penelitian yang dilakukan oleh Fatima dan Ajmal (2012) dengan judul "Happy Marriage: A Qualitative Study" untuk mengetahui faktor-faktor yang menyebabkan kehidupan pernikahan menjadi bahagia menemukan bahwa ada enam belas faktor yang mempengaruhi kebahagiaan dalam kehidupan pernikahan pada wanita yaitu kesamaan agama, kepuasan, kompromi, cinta, care, trust dan saling memahami, komunikasi, perbedaan usia, ketulusan dan respect, saling berbagi, saling memaafkan, tempramen pasangan, kekuatan menjaga anak, struktur keluarga, pendidikan dan status hubungan hukum yang positif. Hal ini juga terbukti berdasarkan hasil analisis dengan analisis regresi berganda diperoleh hasil bahwa ada peran intensitas komunikasi perkawinan terhadap kebahagiaan perkawinan pada istri tentara saat menjalani long distance marriage.

Intensitas komunikasi pada suami istri yang menjalani LDM dengan suami istri yang tinggal serumah dapat berbeda. 
Pada suami istri yang memilih untuk tinggal berjauhan tentunya memiliki intensitas komunikasi langsung yang cenderung rendah, sehingga hal tersebut dapat menjadi salah satu pemicu dalam konflik rumah tangga (Firmin, Firmin, \& Lorenzen, 2014). Intensitas komunikasi mencakup aspek seperti kejujuran, keterbukaan, pengertian, percaya yang mutlak diantara kedua belah pihak dan dukungan (Oslon, 1992). Diharapkan semakin sering anggota keluarga dalam hal ini pasangan suami istri berinteraksi, maka kepercayaan dapat tercipta sehingga hal tersebut dapat menimbulkan kebahagiaan dalam diri pasangan.

Penelitian yang dilakukan oleh Sasmita (2014) menunjukkan bahwa kebahagiaan dipengaruhi intensitas komunikasi sebesar $24,3 \%$ dan sisanya 75,7 $\%$ dipengaruhi oleh faktor lain yang mempunyai pengaruh lebih besar. Semakin sering pasangan yang sedang menjalani pernikahan jarak jauh berkomunikasi, maka semakin bahagia pernikahan mereka. Selain itu, perhatian yang diberikan saat berkomunikasi juga bisa sebagai penunjang dalam kebahagiaan pernikahan jarak jauh (Devito, 2009).

Berdasarkan hasil analisis dengan analisis regresi berganda diperoleh hasil bahwa ada peran kepercayaan perkawinan terhadap kebahagiaan perkawinan pada istri tentara saat menjalani long distance marriage. Hal ini ini memperkuat teori yang dikemukakan oleh Rempel, Holmes, dan Zanna (1985) yang menyatakan bahwa kepercayaan perkawinan dapat diukur dari keadaan dapat diramalkan (predictability), keadaan dapat diandalkan (dependability), keyakinan (faith). Bente, Ruggenberg Kraner, dan Eschenburg (Firmin dkk., 2014) menyatakan bahwa kepercayaan adalah komponen kunci dalam keberhasilan suatu hubungan. Pada hubungan jarak jauh, beberapa level kepercayaan harus dikembangkan karena seorang individu tidak dapat mengamati secara langsung kehidupan individu pasangannya. Ketidak- percayaan pada pasangan dapat menimbulkan permasalahan yang pada akhirnya akan menimbulkan ketidaknyamanan dan kebahagiaan dalam hubungan tersebut.

Hal ini sesuai dengan penelitian yang dilakukanoleh Ramadhini dan Hendriani (2015) menunjukkan bahwa keyakinan yang dimiliki terhadap pasangan berperan dalam memperkuat hubungan pernikahan, khususnya dalam long distance marriage. Kepercayaan adalah hal penting dalam suatu hubungan, ketika kepercayaan (trust) ada di antara hubungan (suami dan istri) meskipun mereka berada ditempat yang berbeda, maka kebahagiaan pada suami dan istri yang sedang menjalani pernikahan jarak jauh akan terjaga dan kepercayaan diantara keduanya akan terus terbangun. Resiko kecurigaan istri terhadap suami pun akan berkurang atau bahkan hilang sebaliknya kecurigaan suami pun akan istrinya akan berkurang atau bahkan hilang juga. Pada awalnya trust banyak dikaji dari disiplin psikologi, karena hal ini berkaitan dengan sikap seseorang. Pada perkembangannya, trust menjadi kajian berbagai disiplin ilmu (Kim \& Tadisina, 2003).

Berdasarkan hasil analisis dengan analisis regresi berganda diperoleh hasil bahwa tidak ada peran dukungan sosial perkawinan terhadap kebahagiaan perkawinan pada istri tentara saat menjalani long distance marriage, hal ini dikarenakan dukungan sosial yang didapatkan oleh istri tentara yang berada di batalyon tersebut sudah terpenuhi dengan baik, karena mereka sama-sama mengalami hal yang serupa dan mereka sudah saling memberikan dukungan satu sama lain, sehingga dukungan sosial perkawinan tidak mempunyai peran terhadap kebahagiaan perkawinan. Hasil penelitian yang dilakukan oleh Margiati dan Ekayati (2013) menunjukkan bahwa terdapat hubungan yang sangat signifikan antara stres dan dukungan keluarga dengan agresivitas pada istri yang menjalani pernikahan jarak jauh. Hasil penelitian yang dilakukan oleh Hayati (2011) menun- 
jukkan bahwa hubungan positif yang sangat signifikan antara dukungan sosial pasangan dengan kepuasan pernikahan. Artinya semakin tinggi dukungan sosial pasangan maka akan semakin tinggi kepuasan pernikahan.

\section{Kesimpulan}

Berdasarkan hasil penelitian dan pembahasan yang dilakukan pada bab terdahulu, maka terdapat beberapa poin yang dapat disimpulkan, yaitu: (1) Terdapat peran secara bersama-sama antara intensitas komunikasi, kepercayaan dan dukungan sosial terhadap kebahagiaan perkawinaan pada istri tentara saat menjalani long distance marriage. (2) Terdapat peran pada intensitas komunikasi perkawinan terhadap kebahagiaan perkawinaan pada istri tentara saat menjalani long distance marriage. Semakin tinggi intensitas komunikasi perkawinan maka semakin tinggi tingkat kebahagiaan perkawinan pada istri tentara saat menjalani long distance marriage, begitupun sebaliknya semakin rendah intensitas komunikasi perkawinan maka semakin rendah tingkat kebahagiaan perkawinan pada istri tentara saat menjalani long distance marriage. (3) Terdapat peran pada kepercayaan perkawinan terhadap kebahagiaan perkawinaan pada istri tentara saat menjalani long distance marriage. Semakin tinggi kepercayaan perkawinan maka semakin tinggi tingkat kebahagiaan perkawinan pada istri tentara saat menjalani long distance marriage, begitupun sebaliknya semakin rendah kepercayaan perkawinan maka semakin rendah tingkat kebahagiaan perkawinan pada istri tentara saat menjalani long distance marriage. (4) Tidak terdapat peran pada dukungan sosial perkawinan terhadap kebahagiaan perkawinan pada istri tentara saat menjalani long distance marriage.

\section{Daftar Pustaka}

Anderson, J. R., Ryzin, M. J., Doherty, W. J. (2010). Developmental trajectories of marital happiness in continuously married individuals: a group-based modeling approach. Journal of Family Psychology, 24 (5), 587-596. doi: $10.1037 / a 0020928$

Andjariah, S. (2005). Kebahagiaan perkawinan ditinjau dari faktor komunikasi pada pasangan suami istri. Jurnal Psikologi, 1 (I), 1-5.

Aryani, R. (2009). Komunikasi interpersonal pasangan suami istri keluarga militer dalam menjaga keutuhan dan keharmonisan perkawinan (Unpublished Undergraduate's Thesis). Fakultas IImu Sosial dan IImu Politik, IImu Komunikasi, Universitas Muhammadiyah Yogyakarta, Yogyakarta.

Azwar, S. (2012). Penyusunan skala psikologi. Yogyakarta: Pustaka Belajar.

Billedo, C. J., Kerkhof, P., \& Finkenauer, C. (2015). The use of social networking sites for relationship maintenance in long-distance and geographically close romantic relationships. Cyberpsychology, Behavior, and Social Networking, 18(3), 152157. doi: 10.1089/cyber.2014.0469

Dewi, N. R., \& Sudhana, H. (2013). Hubungan antara komunikasi interpersonal pasutri dengan keharmonisan dalam pernikahan. Jurnal Psikologi Udayana, 1 (1), 22-31.

Devito, J. A. (2009). Essentials of human communication. Pearson College Dision.

Djamarah, S. B. (2004). Pola komunikasi orangtua dan anak dalam keluarga sebuah perspektif pendidikan islam. Jakarta: Rineka Cipta.

Fatima, M., \& Ajmal, M. I. (2012). Happy marriage: A qualitative study. Pakistan Journal of Social and Clinical Psychology, 10 (01), 37-42.

Fatma, S. H. \& Sakdiyah, E. H. (2015). Perbedaan kebahagiaan pasangan pernikahan dengan persiapan dan tanpa persiapan pada komunitas young mommy tuban. Jurnal Psikologi Tabularasa, 10 (1), 103-114. 
Firmin, M, W., Firmin, R, L., \& Lorenzen, K. (2014). A qualitative analysis of loneliness dynamic involved with college long-distance relationship. CollegeStudent Journal, 48 (1), 5771.

Gottman, J. M. (1999). The marriage clinic: a scientifically-based mental therapy. New York: W.W Norton \& Company.

Habibi, U. R. (2015). Kepuasan pernikahan pada wanita yang dijodohkan (wanita yang dijodohkan oleh orangtua). eJournal Psikologi, 3 (2), 579588.

Hayati, R. F. (2011). Hubungan antara dukungan sosial pasangan dengan kepuasan pernikahan. (Unpublished Undergraduate's Thesis) Fakultas Psikologi Universitas Muhammdiyah Surakarta. Diunduh pada http://eprints.ums.ac.id/15330/

Crystal Jiang, L., \& Hancock, J. T. (2013). Absence makes the communication grow fonder: Geographic separation, interpersonal media, and intimacy in dating relationships. Journal of Communication, 63(3), 556-577. doi: 10.1111/jcom.12029

Karney, B. R., \& Crown, J. S. (2007). Families under stress: An assessment of data, theory, and reseach on marriage and divorce in the military (Vol. 599). Rand Corporation.

Kenrick, D. T., Neuberg, S. L., \& Cialdini, R. B. (2007). Social psychology: goals in interaction (4th ed.). United States of Amerika: Pearson Education, Inc.

Kim, E., \& Tadisina, S. (2003). Customer's initial trust in e-business: how to measure customer's initial trust. Proceedings of Ninth Americas Conference on Information Systems (pp. 35-41).

King, L. A. (2012). Psikologi umum sebuah pandangan apresiatif. terj. Marwendsdy, Brian. Jakarta: Salemba Humanika.
Maguire, K. C., \& Kinney, T. A. (2010). When distance is problematic: Communication, coping, and relational satisfaction in female college students' long-distance dating relationships. Journal of Applied Communication Research, 38(1), 27-46. doi: 10.1080/00909880903483573

Margiani, K. \& Ekayati, I. N. (2013). Stres, dukungan keluarga dan agresivitas pada istri yang menjalani pernikahan jarak jauh. Pesona, Jurnal Psikologi Indonesia, 2 (3), 191-198.

Marini, L., \& Julinda. (2010). Gambaran kepuasan pernikahan istri pada pasangan commuter marriage. Fakultas Psikologi Universitas Sumatera Utara. Diunduh pada tanggal 19 April 2016. repository.usu.ac.id/bitstream/12345 6789/19285/5/Cover.pdf

Marvin, R., \& Britner, P. (1999). Normative development: The ontogeny of attachment. in J. Cassidy \& P. Shaver (eds.), Handbook of attachment: theory, research and clinical applications (pp.44-67). New York, NY: Guliford Press.

Merolla, A. J. (2010). Relational maintenance during military deployment: Perspectives of wives of deployed US soldiers. Journal of Applied Communication Research, 38(1), 4-26. doi: $10.1080 / 00909880903483557$

Mijilputri, N. (2015). Peran dukungan sosial terhadap kesepian istri yang menjalani hubungan pernikahan jarak jauh (Long Distance Marriage). E-Journal Psikologi, 3 (2), 477-491.

Oslon, D, H. (1992). Family inventories (manual: family social sciences) UAS: University of Minnesotta.

Pistole, M, C., (2010). Long-distance romantic couples: An attachment theoretical perspective. Journal of Marital and Family Therapy, 36(2), 115-125. doi: 10.1111/j.17520606.2009.00169.x

Pratamasari, A. D. (2016). Trust Pelaku Hubungan Jarak Jauh Wanita Dewasa Muda Terhadap Pasangan- 
nya (Unpublished Undergraduate's Thesis) Universitas Muhammadiyah Surakarta.

Rachmawati, D. \& Mastuti, E. (2013). Perbedaan tingkat kepuasan perkawinan ditinjau dari tingkat penyesuaian perkawinan pada istri brigadif 1 marinir TNI-AL yang menjalani long distance marriage. Jurnal Psikologi Pendidikan dan Perkembangan, 2 (02), 73-80.

Ramadhini, S., \& Hendriani, W. (2015). Gambaran trust pada wanita dewasa awal yang sedang menjalani long distance marriage. Jurnal Psikologi Klinis dan Kesehatan Mental, 4 (1), 15-20.

Rauer, A. \& Volling, B. (2013). More than one way to be happy: a Typologi of marital happiness. Family Process, 52 (3), 519-534. doi: 10.1111/famp.12028

Rempel, J. K., Holmes J. G., \& Zanna M. P. (1985). Trust in close relationship. Journal of Personality and Social Psychology, 49 (1), 95-112. doi: 10.1037/0022-3514.49.1.95

Rindfuss, R. R., \& Stephan, E. H. (1990). Marital noncohabition: separation does not make the heart grow fonder. Journal of Marriage and Family, 52 (1), 259-270. doi: $10.2307 / 352856$

Rini, R. I. (2009). Hubungan antara keterbukaan diri dengan penyesuai- an perkawinan pada pasangan suami istri yang tinggal terpisah. Psycho Idea, 7 (2), 1-13.

Sasmita, D. (2014). Pengaruh intensitas komunikasi dan kebahagiaan pada pernikahan. Fakultas Psikologi Universitas Gunadarma, Jakarta. Diunduh pada tanggal 19 Mei 2016. http://library.gunadarma.ac.id/reposi tory/view/3793708/pengaruhintensitas-komunikasi-dankebahagiaan-pada-pernikahan.html/

Sears, D. O., Freedman, J. L., \& Peplau, L. A. (2006). Psikologi sosial. jilid I. Alihbahasa: Michael Adryanto \& Savitri Soekrisno. Jakarta: Erlangga. Siregar, S. (2013). Statistik parametrik untuk penelitian kuantitatif. Jakarta: PT. Bumi Aksara.

Stafford, L. (2005). Maintaining longdistance and cross-residential relationship. New Jersey: Lawrence Erlbaum Associates, Inc.

Stafford, L. (2010). Geographic distance and communication during courtship. Communication Research, 37(2), 275297. doi: $10.1177 / 0093650209356390$

Zhang, H. \& Tsang S. (2012). Relative income and marital happiness among urban chinese women: the moderating role of personal commitment. J Happiness Stud, 14 (5), 1575-1584. doi: 10.1007/s10902012-9396-5 